\title{
Lipase Catalyzed Naproxen Methyl Ester Enantioselective Hydrolysis in Ionic Liquids
}

\author{
Shengbo Gao", a , Quanhui Li, b, Tingting Yao, c , Zhengyang Wang ${ }^{1, d}$, Luoyun \\ Zheng ${ }^{1, e}$ and Jiaying Xin $^{1, f^{*}}$ \\ ${ }^{1}$ Key Laboratory for Food Science and Engineering, Harbin University of Commerce, China \\ a544546692@qq.com, b1023281117@qq.com, ${ }^{\text {'} 657407999 @ q q . c o m, ~ d 306224963 @ q q . c o m, ~}$ \\ 506637547@qq.com, ${ }^{f^{*}}$ xinjiayingvip@163.com
}

${ }^{*}$ The corresponding author

Keywords: Lipase; Enantioselective hydrolysis; Naproxen; Ionic liquids; Biphasic system

\begin{abstract}
A series of dialkylimidazolium ionic liquids with various anions including hexafluorophosphate alkane sulfonate and tetrafluoroborates were studied in the lipase-catalyzed enantioselective hydrolysis. Lipase activity, stability and enantioselectivity were determined by both of alkane and anions. In the best aqueous- C4mimPF6 biphasic system lipase resolution of Naproxen proceed with much effective. It was observed that the activity of lipase in aqueous- C4mimPF6 system was comparable with that in aqueous-organic system, but the enantiomeric ratio of Lipase-catalysis hydrolysis in aqueous - $\mathrm{C} 4$ mimPF6 biphasic system (E>300) was much higher than that in aqueous -organic biphasic system $(\mathrm{E} \approx 90)$.
\end{abstract}

\section{Introduction}

(S)-(+)-2-(6-Methoxy-2-naphtyl) propionic acid (Naproxen) is a non-steroidal anti-inflammatrory drug and the physiological activity of the S-Naproxen is 28-fold higher than that of R-form[1] .The methods for product S-Naproxen has been intensively explored and enzymatic resolution of Naproxen is efficient and can be performed by hydrolysis[2,3] and esterification[4,5]. As the two methods from the standpoint of high productivity, easy product separation, and few reaction steps, lipase-catalyzed asymmetric hydrolysis has been judged to be superior for the practical resolution of racemic acids [6]. Anterior studies of asymmetric hydrolysis often carry through in aqueous system or in aqueous-organic biphasic system. In the first system the relatively low solubility of substrate cause a low reaction rate [7]. In the second system the substrate can be dissolved in an organic phase, while the emulsion made difficult to separate the product and substrate, decreased the stability of the enzyme, the volatile organic is dangerous and it does not accord with the" Green chemistry" tenet [8].

To overcome the aforementioned problems, room-temperature ionic liquids are an appreciate choice. Ionic liquids have been reported as non-volatile, non-flammable, low toxicity, and good solubility for many organic and inorganic materials. They also be reported can enhance activity, selectivity and stability of catalysts in chemical reactions $[9,10]$, and can dramatically reduce the use of hazardous and volatile polluting organic solvents.

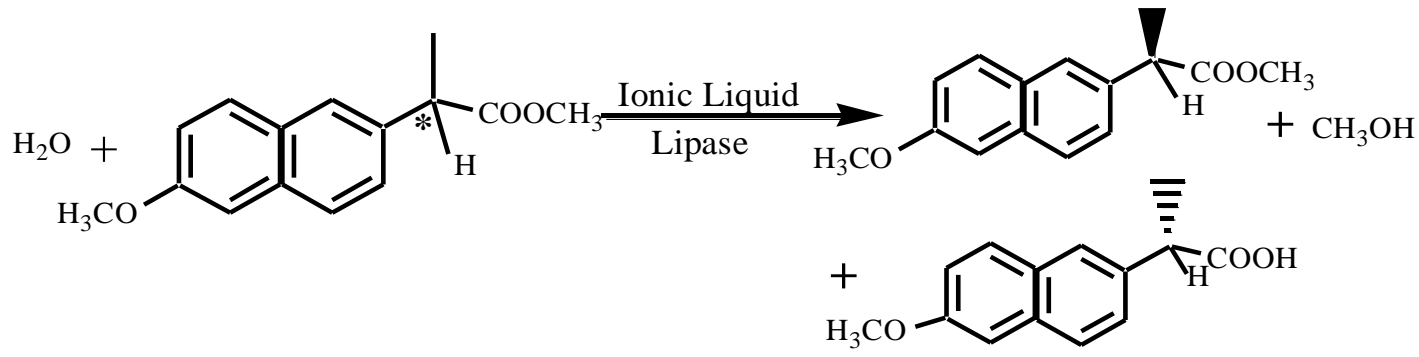

Figure 1. Lipase catalyzed enantioselective hydrolysis of Naproxen methyl ester in aqueous-ionic liquids biphasic system 


\section{Materials and Methods}

Reagents: Lipase typeVII L-1754 from candida rogusa (1140 units/mg Sigma), naproxen methyl ester purified by recrystallization from petroleum ether and dried in vacuum, ionic liquid synthesized and purified according to Parks[11],other reagents were analytical degree and used without any purification.Synthesis of sucrose esters by microwave-assisted lipase-catalyzed reaction.

Analytical Methods In both cases, samples were withdrawn at specified time intervals for measurement of the conversion (C) and enantiomeric excess of the reaction. Firstly, water in aqueous phase was removed by freeze-dryer, and then methanol was used to extract the Naproxen. Hexane was used to extract the remained substrate from ionic liquids phase. The enantiomeric excess of product (eep) and remain substrate (ees) were determined by HPLC using chiral column respectively. Analytical conditions: naproxen methyl ester used Chiralcel OD-H,250×4.6mm hexane/2-propanol $90 / 10(\mathrm{v} / \mathrm{v})$ flow rate $0.5 \mathrm{~mL} / \mathrm{min} \mathrm{UV} 254 \mathrm{~nm}$ at room temperature; naproxen used chiralcel R-NGLY\&DNB, $250 \times 4.00 \mathrm{~mm}$, acetic ammonia dissolve in methanol with $30 \mathrm{mMol} / \mathrm{L}$, flow rate 0.5 $\mathrm{mL} / \mathrm{min}$ UV $254 \mathrm{~nm}$ at room temperature.. The enantiomeric ratio (E) values were calculated using equation: $\mathrm{E}=\ln [1-\mathrm{c}(1+\mathrm{eep})] / \ln [1-\mathrm{c}(1-\mathrm{eep})],[12]$ where $\mathrm{c}=\mathrm{ees} /($ ees + eep $)$.

Enzymatic Resolution of Naprozen. In typical experiments, $125 \mathrm{mg}$ of candida rogusa lipase and $75 \mathrm{mg}$ of substrate Naproxen methyl ester were added into $3 \mathrm{ml}$ of sodium phosphate buffer and $3 \mathrm{ml}$ of ionic liquids the resolution reaction was started by shaking the flask at $32{ }^{\circ} \mathrm{C}(170 \mathrm{rpm})$. As comparing, the same reaction was also performed in aqueous-organic biphase system containing $3 \mathrm{ml}$ of sodium phosphate buffer and $3 \mathrm{ml}$ of isooctane.

\section{Results}

Selection of Ionic Liquids. We synthesized a series of ionic liquids according to Parks[11] in order to study the feasibility of lipase resolution of naproxen in ionic liquids system. The results were given in Table 1

Table 1 the effect of ionic liquid composition on the lipase-catalyzed naproxen methyl ester

\begin{tabular}{cllll}
\hline ionic liquids & ee $(\%)$ & ee $(\%)$ & $\mathrm{E}\left(10^{2}\right)$ & $\mathrm{C}(\%)$ \\
\hline $\mathrm{C}_{4} \mathrm{mimPF}_{6}$ & 35.60 & 99.40 & $>3.0$ & 26.40 \\
$\mathrm{C}_{4} \mathrm{mimBF}_{4}$ & 8.00 & 98.70 & 1.6 & 7.50 \\
$\mathrm{C}_{6} \mathrm{mimPF}_{6}$ & 17.50 & 98.80 & 1.9 & 15.00 \\
$\mathrm{C}_{6} \mathrm{mimC}_{7} \mathrm{SO}_{3}$ & 7.40 & 98.00 & 1.0 & 7.00 \\
$\mathrm{C}_{6} \mathrm{mimBF}_{4}$ & 6.20 & 99.00 & 2.1 & 5.90 \\
$\mathrm{C}_{8} \mathrm{mimBF}_{4}$ & 4.80 & 98.50 & 1.4 & 4.60 \\
\hline
\end{tabular}

hydrolysis $^{\mathrm{a}}$

L-1754=125mg; naproxen methyl ester $=75 \mathrm{mg}$; $\mathrm{PH}=7.0$; tempreture $32.0^{\circ} \mathrm{C}$; $170 \mathrm{r} / \mathrm{min}$; sample in the fifth day. Ionic liquid/sodium phosphate buffer $(\mathrm{v} / \mathrm{v})=1 / 1$. $(3 \mathrm{ml} / 3 \mathrm{ml})$

With the same alkylmethyllimidazolium the enzyme activity and diastereomeric selectivity have relations with the anion, in our experimentation was PF6 >BF4>C7SO3; with the same anion condition the relationship of enzyme activity and diastereomeric selectivity with the alkyl length was $\mathrm{C} 4>\mathrm{C} 6>\mathrm{C} 8$. For this reason we choose $\mathrm{c} 4 \mathrm{mimPF} 6$ for the follow experience.

According to our previous report [13] water content is a sensitive factor of lipase activity in biphasic system. So the effect of water content in the reaction medium on the conversion $(C)$, the 
enantiomeric excess of product (eep)、 remain substrate (ees) and enantiomeric ratio (E) was studied. As shown in Table 2

Table2 The effects of the water content in the biphase system on the Conversion, enantiomeric excess and enantiomeric ratio (E)

\begin{tabular}{lllll}
\hline $\begin{array}{l}\text { ionic } \\
\text { liquids:Aque } \\
\text { ous (v/v) }\end{array}$ & $\mathrm{ee}_{\mathrm{s}}(\%)$ & $\mathrm{ee}(\%)$ & $\mathrm{E}\left(10^{2}\right)$ & $\mathrm{C}(\%)$ \\
\hline $3: 1$ & 18.40 & 99.00 & & \\
$2: 1$ & 27.40 & 99.10 & 2.4 & 15.70 \\
$2: 2$ & 28.60 & 99.30 & 2.9 & 21.70 \\
$2: 3$ & 22.00 & 98.70 & 13.0 & 22.40 \\
$2: 4$ & 21.80 & 99.00 & 2.5 & 18.20 \\
\hline
\end{tabular}

keep the concentration of lipase L-1754 and naproxen methyl ester invariablenes; PH7.0 ; Temperature $32^{\circ} \mathrm{C} ; 170 \mathrm{r} / \mathrm{min}$, determined at the fifth day.

When the ratio of ionic liquid to aqueous was $1: 1(\mathrm{v} / \mathrm{v})$, both of the conversion and enantioselective was high, however the decline of conversion and enantioselective was found when the water content in the reaction medium was too big or too small. We suspect that it maybe the influence of the reaction interfaces.

In the aqueous -ionic liquids biphasic system, lipase could keep the same activity as in aqueous -organic biphasic system. The advantages of use aqueous -ionic liquids biphasic system are that they can be readily reused but have no infection to the enzyme; and the enantioselective was much higher than that in aqueous -organic biphasic system. Also, ionic liquids are not environment pollutions as organic solvents. The aqueous -organic biphasic system was so facilitate and strong emulsification with water that remain substrate, product and enzyme could hardly be separated after reaction, but the aqueous -ionic liquids biphasic system was not. And using no detectable vapor pressure ionic liquids instead of the volatile organic can make the reaction much safer.

\section{Summary}

In summary, from our research we can observe that aqueous -ionic liquids biphasic system can work as aqueous -organic biphasic system for lipase-catalyzed enantioselective hydrolysis with advantages enhancing the enantioselectivity, avoiding the emulsification and separating the product and substrate easily.

\section{Acknowledgment}

The authors thank the Scientific Research Fund of Heilongjiang Province (GC13C111), the Open Project Program of the State Key Laboratory for Oxo Synthesis and Selective Oxidation for support.

\section{References}

[1] Pandey, A., et al, 1999, "The realm of microbial lipases in biotechnology," Biotechnol.Appl.Biochem. 29, pp. 119-131. 
[2] Battistel, E., et al, 1991, "Enzymatic resolution of(s)-(+)-Naproxen in a continuous reactor," Biotechnol.Bioeng., 38, pp. 659-664.

[3] Chang, CS., Tsai, SW., and Jimmy, K., 1999, "Lipase-catalyzed dynamic resolution of Naproxen 2, 2, 2-trifluoroethyl thioester by hydrolysis in isooctane,Biotechnol.Bioeng" 64, pp.120-126.

[4] Duan, G., et al, 1997, "Kinetic study of Enantioselective esterification of ketoprofen with n-propanol catalysed by a lipase in an organic medium"Biotechnol.Lett." 19, pp.1051-1055.

[5] Tsai, SW., Liu, B.Y., and Chang, CS., 1996, "Enhancement of (s)-Naproxen ester productivity from racemicNaproxen by lipase in organic solvents,"J Chem.Tech.Biotechnol.Biotechnol., 65, pp. 156-162.

[6] Cambou, B., Klibanov, AM., 1984, "Comparison of different strategies for thelipase-catalyzed resolution of racemic acid and alcohols: asymmetrichydrolysis, esterification, and transesterification,'Biotech Bioeng., 26, pp. 1449-1454.

[7] Akita, H., et al, 1989, "Enzymatic hydrolysis in organic solvents for kinetic resolution of water-insoluble a-acyloxy esters with immobilized lipase," Chem Pharm.Bull., 37,pp. 2876-2878.

[8] Elaiwi, A., et al, 1995, "Hydrogen bonding in imidazolium salts and its implications for ambient-temperature halogenoaluminate (III) ionic liquids," J.Chem. Soc DaltonTrans., pp. 3467-3472.

[9] Kim, K.W., et al, 2001, "Biocatalysis in Ionic Liquids: Markedly Enhanced Enantioselectivity of Lipase,” Org. Lett., 3, pp. 1507-1509.

[10] (a) Welton, T., 1999, "Room-Temperature Ionic Liquids Solvents for Synthesis and Catalysis," Chem Rev., 99, pp. 2071-2083 (b) Olivier, H., 1999, "Recent developments in the use of non-aqueous ionic liquids for two-phase catalysis," J. Mol. Catal. A: Chem., 146, pp. 285-289. (c) Wasserscheid, P., and Keim, W., 2000, "Ionic Liquids-"News" Solutions for Transition Metal Catalysis, Angew.Chem.Int.Ed.Engl” 39, pp. 3772-3789. (d) Olivier, H., and Magna, L., 2002, "Ionic liquids: perspectives for organic and catalytic reactions," J. Mol. Catal. A: Chem., 182-183, pp. 419-437.

[11] Seongsoon, P., and Romas J. K., 2001, "Improved Preparation and Use of Room-Temperature Ionic Liquids in Lipase-Catalyzed Enantio- and Regioselective Acylations," J. Org. Chem., 66, pp. 8395-8401

[12] Chen, C.S., et al, 1982, "Quantitative Analyses of Biochemical Kinetic Resolutions of.

[13] Xin, J.Y.,et al, 2000, "Enzymatic resolution of S-naproxen in a trapped aqueous-organic solvent biphase continuous reactor. "Biotechnol. Bioeng., 68, pp.78-83 